\title{
LA IGLESIA DE LA VILLA DE ONTÍGOLA (TOLEDO), VECINA DEL REAL SITIO DE ARANJUEZ
}

\section{The Parish Church of Ontígola (Toledo), Neighbor of the Royal Site of Aranjuez}

\author{
Adolfo DE MINGO LORENTE \\ Universidad de Castilla-La Mancha \\ Adolfo.deMingo@uclm.es
}

Fecha de recepción: 18/07/2020

Fecha de aceptación definitiva: 25/02/2021

RESUMEN: Este artículo repasa la evolución de la iglesia de Ontígola y su relación con Aranjuez, que a mediados del siglo XVIII financió sus obras con cargo a los materiales empleados para la reconstrucción del Real Sitio tras el grave incendio de 1748. Reconocida por Santiago Bonavia un año más tarde, la nueva iglesia de la Purísima Concepción sería finalmente construida por el alarife Florencio Rodríguez del Castillo, según recoge el expediente conservado en el Archivo General de Palacio. Cerrado por amenaza de ruina en 2004 y parcialmente demolido después, el edificio comenzó a ser restaurado a comienzos de 2020.

Palabras clave: arquitectura religiosa; arquitectura barroca; siglo XVIII; Real Sitio de Aranjuez (Madrid); Ontígola (Toledo).

ABSTRACT: This article reviews the evolution of the church of Ontígola and its relationship with Aranjuez, which in the mid-18th century financed its works with the materials used for the reconstruction of the Royal Site after the serious conflagration of 1748. Recognised by Santiago Bonavia a year later, the new church of the Immaculate Conception would finally be built by the master builder Florencio Rodríguez del Castillo, according to the file preserved in the General Archive of the Royal Palace in Madrid. Closed due to the threat of ruin in 2004 and partially demolished later, the building began to be restored at the beginning of 2020 . 
Key words: Sacral Architecture; Baroque Architecture; 18th Century; Royal Site of Aranjuez (Madrid); Ontígola (Toledo).

La villa de Ontígola es un municipio de la provincia de Toledo situado a escasos kilómetros de Aranjuez. Sus casi 4.500 vecinos lo convierten hoy en uno de los enclaves más poblados de la comarca de la Mesa de Ocaña, una magnitud muy alejada de sus reducidas dimensiones en el siglo XVIII, cuando fue construida la iglesia y el pequeño camposanto se convirtió en pionero de los modernos enterramientos en España, ya que su creación tuvo lugar en $1776^{1}$, es decir, más de diez años antes de que Carlos III promulgase su conocida real cédula sobre cementerios extramuros (lo que podría convertirlo en el más antiguo de nuestro país $)^{2}$. Pese a su reducido tamaño, Ontígola poseía gran importancia para satisfacer las necesidades del vecino Real Sitio. No solamente sirvió como lugar de eterno descanso para algunos de sus moradores, sino también como residencia de diplomáticos extranjeros durante las estancias de la Corte en Aranjuez, entre ellos el embajador británico sir Benjamin Keene (1697-1757)3.

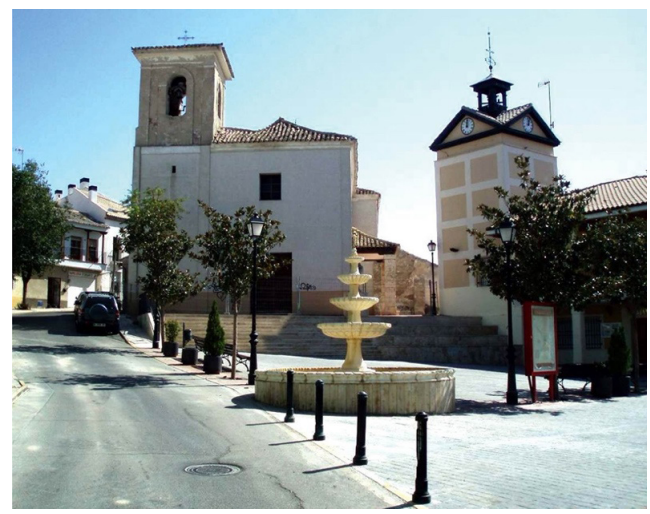

Vista de la iglesia y del vecino ayuntamiento desde la calle Mayor (imagen de 2009).

1. Madoz, Pascual. Diccionario Geográfico-Estadístico-Histórico de España y sus posesiones de Ultramar. Madrid: Imprenta del Diccionario de Pascual Madoz, 1849, p. 285.

2. La construcción de este temprano cementerio estaría coincidiendo en fechas, de hecho, con el real decreto promulgado en París ese mismo año (1776) por el monarca Luis XVI. Carlos III no encargó hasta 1783 la construcción del camposanto del Real Sitio de La Granja de San Ildefonso, que sería finalizado dos años después. Una primera real orden, dictada el 3 de agosto de 1784, prohibía las inhumaciones en el interior de las iglesias. Tres años después se promulgará la famosa real cédula de 3 de abril de 1787, ordenando la instalación de cementerios. La implantación eficaz de estas medidas no se haría realidad hasta mucho después, ya iniciado el siglo XIX.

3. LODGE, Richard. The private correspondence of Sir Benjamin Keene, KB. Cambridge: University Press, 1933. 


\section{EL PRIMITIVO TEMPLO}

Las fuentes históricas sobre la antigua iglesia de Ontígola, anterior a la construcción del siglo XVIII, son escasas y dispersas. Las de época medieval apuntaban más bien hacia el castillo de Oreja, situado dentro del término municipal y cabeza de una antigua encomienda de la Orden de Santiago que tuvo cierta importancia como cabeza de puente sobre el río Tajo, en cuya ribera madrileña se encuentra, precisamente, la localidad de Colmenar de Oreja ${ }^{4}$. Mencionada por primera vez con el nombre de Fonticulam en el fuero de Oreja (1139), Ontígola dependía en el siglo XII de la cercana población de Ocaña ${ }^{5}$. Posteriormente será dotada de fuero propio (1202) por el maestre don Gonzalo Rodríguez, pasando el ejido de la villa y sus dehesas a depender de la mesa maestral de la Orden de Santiago.

La presencia del templo pasa entonces casi inadvertida. Tampoco abundan en detalles los testimonios transmitidos a lo largo de la Edad Moderna, momento en que las canteras del término municipal surtieron a la construcción y desarrollo del Real Sitio. Será necesario esperar hasta la Descripción histórica del Real Bosque y Casa de Aranjuez (1804), de Juan Antonio Álvarez de Quindós, para conocer algunos detalles acerca de la reconstrucción y ampliación del templo ${ }^{6}$. Una información que ahora es posible complementar gracias a la documentación conservada en el Archivo General de Palacio y el Archivo Histórico Diocesano de Toledo.

Son varias las referencias a otros templos construidos en los alrededores de Ontígola desde época medieval, como «un suntuoso templo dedicado a San Miguel que aún existía en 1463" en el "notable» despoblado de Ocañuela, según apuntó Miguel Díaz Ballesteros en 18687. Juan Antonio Álvarez de Quindós, por otra parte, recogió para subrayar la gran antigüedad de este territorio que los vecinos de Oreja emplearon piedras con inscripciones antiguas para construir la antigua iglesia que junto al castillo poseía aquel poblamiento, templo sobre el cual se han conservado muy pocos testimonios ${ }^{8}$. Conviene añadir aquí el antiguo

4. El estado de ruina avanzada del castillo motivó que la asociación Hispania Nostra lo incluyera dentro de su "Lista Roja» en 2013. Tres años después, la Real Academia de Bellas Artes y Ciencias Históricas de Toledo reivindicaría nuevamente a través del medievalista Ramón Gonzálvez Ruiz (1928-2019), exdirector de esta institución, una consolidación del edificio por parte de las autoridades competentes que todavía no se ha producido. Para mayor información sobre la historia del castillo, LARRÉN Izquierdo, Hortensia. El castillo de Oreja y su encomienda. Toledo: Instituto Provincial de Investigaciones y Estudios Toledanos (IPIET), 1984.

5. García SÁnchez, Jairo Javier. Toponimia mayor de la provincia de Toledo. Toledo: IPIET, 2004, pp. 266-268.

6. Álvarez de Quindós, Juan Antonio. Descripción histórica del Real Bosque y Casa de Aranjuez. Madrid: Imprenta Real, 1804.

7. Díaz Ballesteros, Miguel. Historia de la villa de Ocaña. Ocaña: Imprenta de Agustín Puigrós, 1868.

8. El Archivo Histórico Nacional (AHN) ha conservado, dentro del rico fondo santiaguista de Uclés, las conclusiones de los visitadores de la orden en los años de 1537, 1602 y 1603/1605, etapa tras la desmembración de la encomienda, que se encontraba ya en plena decadencia, por parte de 
cenobio de Ciruelos, localidad vecina de Ontígola donde vivió sus últimos días y fue sepultado san Raimundo de Fitero antes del posterior traslado de sus restos al monasterio cisterciense de Montesión de Toledo. Poco ha quedado de las construcciones de aquellos momentos en esta zona de la provincia de Toledo. Según Fernando Jiménez de Gregorio, «los antiguos templos mudéjares que hubiera en la comarca [de la Mesa de Ocaña] serían derribados por ruinosos y reemplazados por construcciones gótico tardías y renacentistas, por eso las centurias XVI y XVII son pródigas en monumentos eclesiales»?.

Este parece haber sido el caso de la primitiva iglesia de Ontígola, que Juan Antonio Álvarez de Quindós situaba inicialmente en el cerro de San Cristóbal y que no se habría trasladado hasta su actual ubicación hasta 1537, cuando tomó el nombre de Nuestra Señora de la Concepción. La localidad permanecía unida a la suerte de Aranjuez desde finales de la Edad Media, momento en el que Ontígola disfrutaba incluso de jurisdicción parroquial sobre sus vecinos.

Carlos I (1540). Las iglesias de Ontígola y Oreja compartían en aquel entonces su advocación a Nuestra Señora de la Concepción, una excepción dentro de la tradición santiaguista de dedicar sus templos a la Asunción de la Virgen María (la iglesia de Oreja, de hecho, adquiriría esta denominación posteriormente). Es probable que ambos templos compartieran una morfología semejante en el siglo XVI, consistente en sencillas cubiertas de parhilera con rollizos de madera de pino conducido hasta aquí por las aguas del Tajo, ladrillo para los refuerzos estructurales y paredes de mampostería enlucidas. Este es el testimonio de 1537 sobre la iglesia de Oreja: «E luego fueron a la yglesia de Nuestra Señora, cuya advocacion es la dicha villa y en la qual visitaron con vecinos. Yglesia de tres naves pobre, cuatro pilares de ladrillo, la capilla esta encubierta de armadura de pino. Ay en ella tres altares quel altar mayor y un retablo pequeño y dentro del una imagen de Nuestra Señora de la Concepción. Estaba adereçado de ornementos mantes e palio e frontal. Los otros dos altares estaban con sus manteles y frontales bien adereçados» (AHN, Uclés, Libro 1.081, ff. 647-658). En 1537 se reconoció asimismo la ermita de San Andrés, situada junto al primitivo embarcadero de Oreja, a orillas del río, espacio documentado desde al menos 1226, según Jiménez de Gregorio: «Visitose una ermita de Santo Andres que esta junto a la barca de Oreja; es de un cuerpo, esta cubierta de madera de pino. Tiene un altar con un retablo pequeño pintado, en que esta la imagen de Nuestra Señora, e de Santo Andres. Hay unos manteles y un frontal pintado». Poco más puede extraerse de las visitas de 1602 y 1603-1605, salvo los esfuerzos para aderezar su iglesia de los habitantes de las cuarenta casas de vecinos que Oreja conservaba aún a mediados del siglo XVI, según mencionan las Relaciones de Felipe II al tratar sobre Ocaña. En 1602, los visitadores «luego fueron a la yglesia de dicha villa [Oreja], que es de adbocacion de Nuestra Señora de la Concepcion, con un retablo muy bueno con la ymagen de Nuestra Señora de la Concepcion" (AHN, Uclés, Libro 11, f. 94v.). Algo similar se dijo en la visita de 1603-1605: "Yglesia. Luego fueron a la yglesia de la dicha villa tiene la advocacion de Nuestra Señora de la Concepcion. Las paredes son enlucidas con cubiertas de madera a dos aguas. Tiene un retablo nuevo e muy bueno con la imagen de Nuestra Señora de la Concepcion e con la de San Pablo e con la de los doce apostoles" (AHN, Uclés, Libro 6). El Instituto Geográfico Nacional conserva una magnífica y poco conocida planta de la iglesia de Oreja (junto a la que aparece también el resto de esta población, incluido el castillo) realizada por el topógrafo Estanislao Lacaci en 1880.

9. JimÉnEZ De GREGorio, Fernando. La comarca de la Mesa de Ocaña. Toledo: Diputación, 1996, p. 35 


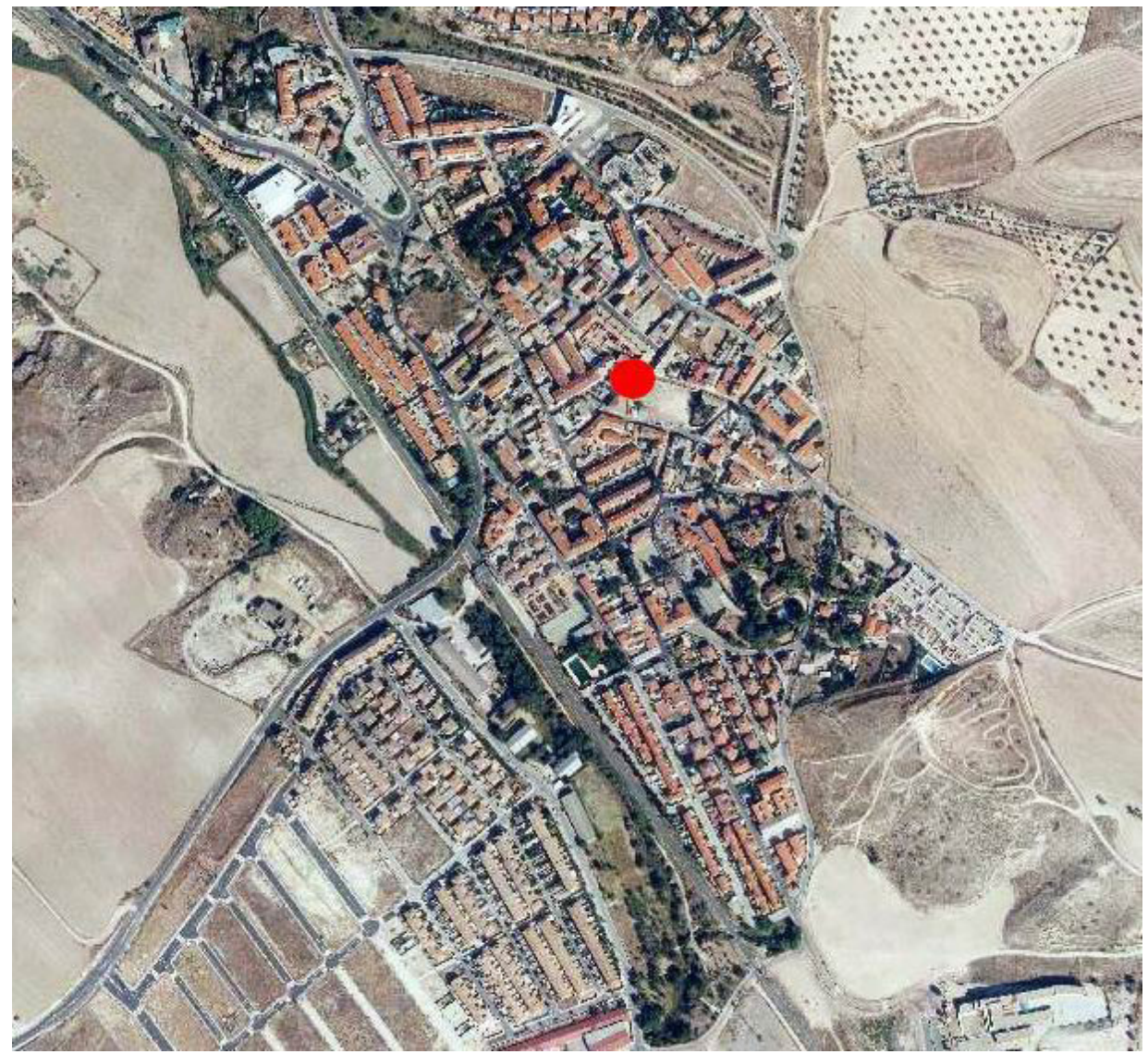

Localización del templo dentro del término municipal.

No en vano, «al Curato de Hontígola pertenece lo de Alpaxés y de Aranjuez por derecho adquirido de muy antiguo", añade Álvarez de Quindós, "sin que haya noticia que [Ontígola] pueda haberlos adquirido despues quando [Aranjuez] ha estado mas poblado y asistido» ${ }^{10}$. Más adelante, el autor de la Descripción histórica del Real Bosque y Casa de Aranjuez recoge como:

[...] el licenciado Fulgencio de Mora, Cura de Hontígola, defendió con órden del Cardenal Arzobispo de Toledo, y se opuso á que los primeros Capellanes que se estableciéron en Aranjuez, hiciesen la administracion de Sacramentos como propio que era de su Curato.

10. Álvarez De Quindós, Juan Antonio, Descripción histórica..., p. 54. 
Sea como fuere, ni Ontígola ni Oreja, ni tampoco la mayoría de los catorce municipios que forman hoy la comarca de la Mesa de Ocaña, a excepción de cinco -el pequeño Ciruelos era uno de ellos, cuya iglesia apenas se mencionaba, sin ningún elemento destacable-, fueron consignados en las Relaciones de Felipe II. Es posible aventurar, sin embargo, que la situación de la parroquia anterior a las obras de 1537 fuera razonablemente desahogada, ya que el comendador de Alpajés estaba obligado a mantenerla:

Como percibidor de ellos [los diezmos] tiene el Comendador la obligacion de mantener la Iglesia Parroquial de Hontígola, y dar á sus vecinos el pasto espiritual. Es patrono de la misma Iglesia, y así consta en sus libros que intervenia en las cuentas de la fábrica, y se halla tomada una en 30 de noviembre de 1533 por el Cura y por Ruy Perez, Mayordomo de Don García de Toledo, que era el Comendador.

El informe de ruina elaborado antes de la obra del siglo XVIII permite conocer algunos detalles acerca de cómo era la primitiva iglesia o, más bien, cómo se encontraba en 1749, "de tapias de tierra desplomadas, que han despedido las maderas de su techumbre con evidente, y conocido riesgo de arruinarse» ${ }^{11}$. El templo sería reconocido ese mismo año por el arquitecto italiano Santiago Bonavia (1700-1760), responsable de la nueva configuración dieciochesca del Real Sitio de Aranjuez y de edificios tan singulares como la nueva iglesia de Alpajés. Este precisó que:

[...] la Iglesia era de 18 pies de ancho, y 63 de largo, y su altura de tapias de 16 pies y medio, y su cuvierta de un artesonado antiguo, y toda su fabrica de tapias de tierra, con rafas de yeso; Que en el medio de las dos fachadas, o, lineas laterales, en la extension de quarenta pies estavan desplomadas las tapias pie y medio, llevandose tras sí el artesonado; de forma que en muchas partes estavan del todo desunidas y desencajadas las vigas, y que a no tener por una parte el arrimo de la torre y por otra el de la sacristia, y Portico, se huviera undido en el todo; por lo que era indispensable desmontar todo el cuvierto y las tapias desplomadas, y hazer de nuevo los cimientos de mamposteria, y levantar las tapias, poniendolas unos votareles para maior firmeza, y sentar la armadura nueva, haciendo un encamonado para que no quedase la Igl.a a teja vana, con cielo raso alistonado que formase un esquilfe, y blanquear toda la Igl.a y toda la dha obra la taso en 16,275 r.s de v.n. ${ }^{12}$.

11. Madrid. Archivo General de Palacio (AGP). Administraciones Patrimoniales, Aranjuez, C. ${ }^{a}$ 14189: Justificazion de la Ruina que amenaza la Igla. Parroql. de la Villa de Ontigola, sujeta al Rl. Sitio de Aranjuez, y nueva pretension que tienen el Cura y Vezinos de ella de que por $S$. M. se les conceda lizencia para fabricar nueva Iglesia en el Atrio de la antigua.

12. AGP. Administraciones Patrimoniales, Aranjuez, C. ${ }^{a} 14189$. 


\section{LA OBRA DEL SIGLO XVIII}

La principal fuente para conocer las obras de construcción de esta iglesia a mediados del siglo XVIII es el expediente conservado en el Archivo General de Palacio. Juan Antonio Álvarez de Quindós, además, mencionó no solo la ampliación del templo durante el reinado de Fernando VI, sino la posterior creación de un cementerio exento en tiempos de Carlos III. Esta es la breve referencia que dio el cronista de Aranjuez, la cual incluye el presupuesto de 16.712 reales propuesto por Bonavia, recogido al final del epígrafe anterior:

El año de 1749 se ofreció repararla, y el Rey dió diez y seis mil setecientos y doce reales; pero los vecinos ofreciéron suplir lo restante para hacerla de nuevo con cinco pies mas de ancho y quince de largo, y S.M. dió licencia para ello. Por lo estrecho del cementerio se mandó hacer el año de 1765 una bóveda para sepultar los cadáveres que subian de Aranjuez, pues en el pavimento no habia bastantes sepulturas [...] Para evitar estos inconvenientes, y que fuesen ménos los que se pusiesen la Parroquia, resolvió el Señor Don Cárlos III, en su Real Orden de 31 de Agosto de 1775 , se construyese en un sitio baldío, no muy distante de la villa, un campo santo con cerca alta de mampostería, y en él una capilla con un quadro de Animas, y su campana para llamar al pueblo, mandando se enterrasen en él los pobres que no dexasen con que pagar sepultura, y que quedase sin uso el cementerio que estaba cerca de la Iglesia. Concluida la obra, se dió licencia por el Arzobispo de Toledo para su bendicion al Cura de Hontígola en 28 de Setiembre de 1775; y aquel Párroco lo executó en 15 de Junio de [1]776, invocando por patrono y tutelar al glorioso San Márcos Evangelista ${ }^{13}$.

Son de destacar no solo las referencias a la iglesia como espacio para la liturgia, sino también como lugar de enterramiento, siendo sus reducidas dimensiones lo que motivaría la creación del cementerio. Un camposanto que, al menos durante sus primeros años, no evitó que siguieran siendo sepultados aún en el interior del templo personalidades procedentes de Aranjuez, como José de Gálvez y Gallardo (1720-1787), marqués de Sonora, visitador general de la Nueva España y secretario de Estado del Despacho Universal de Indias, cuyos restos serían retirados de allí más adelante. Un nuevo cementerio municipal sería construido entre 1833 y 1839, cuyo coste se estimó en 4.400 reales, siendo necesario vender unas tierras de los propios de la villa ${ }^{14}$.

Pese al reducido vecindario de la localidad en el siglo XVIII, estudiado por Fernando Jiménez de Gregorio, Ontígola atravesó en aquellos momentos por una de sus mejores etapas. En 1761 era nombrado capellán de Aranjuez y cura de la villa de Ontígola Francisco Rodríguez de Campomanes (1724-1810), hermano del

13. Álvarez de Quindós, Juan Antonio, Descripción histórica..., p. 104.

14. Briones Toribio, Luis Bernardo: Corroto Briceño, Jesús y Maquedano Carrasco, Bienvenido. Las líneas del patrimonio histórico. Planos del siglo XIX de la provincia de Toledo. Toledo: Diputación, vol. II, pp. 138-139. 
célebre ministro y jurisconsulto ilustrado ${ }^{15}$. Por otra parte, ya se ha destacado aquí la residencia de personalidades extranjeras tan importantes como el embajador Keene, quien se carteó desde la localidad con Abraham Castres (†1757), cónsul británico en Lisboa. Por ese motivo resulta paradójico que en 1712 tuvieran su domicilio en Ontígola solamente 56 vecinos, siendo el penúltimo en población de la Mesa de Ocaña. Peor sería la situación entre 1752 y 1787, cuando resultó ser el término menos poblado de toda la comarca, con 54 vecinos, 291 habitantes y 36 casas (cinco de las cuales eran cuevas), con un eclesiástico y un hidalgo ${ }^{16}$.

Fue en ese contexto cuando se inició la construcción de la nueva iglesia. El día 25 de mayo de 1749, el cura y los feligreses de la villa elevaron su petición a Fernando VI «y expusieron en un memorial la proxima ruina que amenazava la Iglesia, cuios Diezmos y Primicias percivia SM, y pidieron que se sirviese mandarla reconozer, apear y rehedificar». Atendido el suplicatorio, Santiago Bonavia visitó y peritó el edificio ${ }^{17}$. El expediente incluye algunas referencias sobre la situación de la parroquialidad de Ontígola en aquel momento, incluido el nombre del perceptor de las escasas rentas de la iglesia y mayordomo de fábrica, Juan Narciso, capellán del Real Sitio de Aranjuez. Los diezmos del término de la villa rentaban a la Corona como poseedora en aquel momento de la encomienda de Alpajés, mientras que el monasterio santiaguista de Uclés recibía la décima.

El 7 de octubre de ese mismo año, el arquitecto interventor de Palacio, Juan Ruiz de Medrano ${ }^{18}$, redactaría un amplio memorial dividido en once puntos sobre los requerimientos de la nueva construcción, que por primera vez reproducimos aquí:

15. Vallejo García-Hevia, José María. "Campomanes, la biografía de un jurista e historiador (1723-1802)". Cuadernos de Historia del Derecho, 1996, 3, p. 108.

16. Datos del Catastro de Ensenada, versión digital (disponible en http://pares.mcu.es/Catastro). La referencia concreta, dentro de "Ontígola», se recoge en el archivo de imagen AGS_CE_RG_ L616_282.jpg (consultado el 13/06/2020).

17. Tovar Martín, Virginia. "Santiago Bonavia, arquitecto principal de las obras reales de Aranjuez». Anales de Historia del Arte, 1997, 7, pp. 123-156.

18. Juan Ruiz de Medrano aparece mencionado en diversas obras reales durante el segundo tercio del siglo XVIII. Era hermano de Francisco Ruiz, arquitecto de referencia en la Guadalajara de la primera mitad del siglo XVIII, y con él trabajó en el derribo del viejo colegio de niños de San Buenaventura de Pastrana en 1732. El nombramiento del también guadalajareño Baltasar de Elgueta como nuevo intendente general de las obras del Real Palacio el 21 de junio de 1742 permitiría promocionar a los hermanos Ruiz, convertidos en arquitecto interventor y su teniente. Seis años después, Juan Ruiz de Medrano acabaría sustituyendo a su hermano (AGP, Administraciones Patrimoniales, Real Sitio de Aranjuez, caja 14184, legajo 23). Entre las obras en las que participó es posible destacar la reforma de los jardines del palacio de la Real Quinta del Pardo (1745), el trazado del nuevo viaje de agua de Amaniel (1746) y la Real Fábrica de Cristales de San Ildefonso (1747). Su actividad en Aranjuez fue intensa tras el incendio de 1748, colaborando estrechamente con Santiago Bonavia, a la sazón arquitecto director de las obras reales, tanto en el plan general urbano de este real sitio (1749) como en la reforma del propio palacio, de cuyo estado realizó un informe el 2 de abril de 1751 (AGP, AP, Real Sitio de Aranjuez, caja 14193). 
Condiciones con que se deberà ejecutar la obra, y reparos, que necesita la Yglesia Parroquial de la Villa de Ontigola:

1. ${ }^{a}$ Que se han de demoler las armaduras, que cubren el Cuerpo de Yglesia, apartando toda la madera, tabla, clavazon, y teja, que pueda servir, apilandola segun sus clases en el paraje mas comodo, para que se buelba, â provechar.

2. ${ }^{\text {a }}$ Que las dos paredes, que oy forman el Cuerpo de Yglesia, se han de demoler enteramente, y tambien los Cimientos, sobre que cargan, sacando toda la piedra, de que estan macizos en su profundidad, apartandola donde no estorve, para que vuelva, â servir.

3. ${ }^{a}$ Que las zanjas que nuevamente se habran, para hacer las dos lineas de cimientos, (que estos han de ser de fabrica de mamposteria de piedra, y cal, siendo las mezclas de dos espuertas de arena, de buena calidad, y una de cal, y de iguales cavidas), han de tener tres pies de gruesso, y desde el piso de la Yglesia, han de profundizar seis pies, (estos, aunque se encuentre el firme por razon de las sepulturas, que contra ellos se havren, para su seguridad) y han de subir un pie mas, que el piso de la Yglesia.

4. ${ }^{a}$ Que en cada una de dichas dos linias, se han de elejir sobre los cimientos diez pilares de mayor, repartidos â iguales distancias, y â de tener cada uno quatro pies de ancho, ò paramento, tres de alto, y dos pies, y tres quartos de gruesso; Y su fabrica ha de ser de piedra, y yeso, dejando en los costados de cada pilar sus enjarjes, para travazon, de los cajones de tierra, de que han de ser cada uno de los claros, que quedan entre Pilar y Pilar, dando à la tierra, de que se han de hacer quatro bueltas de hazadon, para prepararla. Y que los cajones queden bien pisados. Y sobre los referidos pilares de mayor se elegiran los de menor de â tres pies de paramento, por tres de alto, y dos, y tres quartos de gruesso, con los mismos enjarjes en sus costados, para la trabazon de los cajones de tierra que han de formar el segundo Ylo de Tapias; prosiguiendo en la misma forma con Pilares de mayor, y menor, y cajones de tierra hasta la altura de diez y ocho pies que han de tener las dos lineas del Cuerpo de Yglesia desde encima de sus cimientos, que son seis Ylos den Tapias de â tres pies de alto cada uno, hechando en ellos sus cintas de yeso.

5. ${ }^{a}$ Que sobre los expresados seis Ylos de Tapias en cada uno de sus Pilares, se han de sentar nudillos, los quales han de tener de largo dos pies, y medio, y sobre ellos, se sentaran las carreras de Vigas sesmas labradas interiores, y exteriores, las unas para sentar el Alero, y las otras sobre que han de cargar los Tirantes del Cuerpo de Yglesia, macizando el hueco de entre unas, y otras de yeso, y cascote. Ylos Tirantes (respeto de que el ancho de la Yglesia son diez, y ocho pies) podran ser de Viguetas de â veinte, y dos pies de largo, de marcos cumplidos, deshiladas por el canto, repartiendolas tres y quatro al tramo, y sobre ellas se sentaràn los estrivos de Vigas sesmas labradas.

6. ${ }^{\mathrm{a}}$ Que la Armadura que nuevamente se haga para cubrir el Cuerpo de Yglesia ha de ser de parilera â dos aguas y los pares de madera de â ocho para que tengan bastante cuerpo, repartiendolos quatro y cinco al tramo, y su ilera ha de ser de Viga sesma serrada por el canto, y labrada â un gruesso. Toda la armadura se cubrirà con tablas de ripia, y en ella se dejaran dos guardillas con sus cercos, correas y tirantillas, para ventilacion del desban, y sus maderas. 
7. ${ }^{a}$ Que la expresada armadura, y sus guardillas se han de tejar con barro â lomo cerrado, hechando caballetes, y respaldos de yeso, aprovechando toda la Teja vieja, que pueda servir, poniendo nueva la que faltase.

8. ${ }^{a}$ Que los Aleros de las dos linias del Cuerpo de Iglesia se han de hacer con canecillos en tosco de la madera bieja, que saliere de las armaduras demolidas dandolos el vuelo correspondiente, y que entren debajo del estrivo p. ${ }^{a}$ su segu[ri] dad, clavandolos contra la carrera exterior, y entomizandolos tejidos para forjar sus huecos con yeso, y cascote formando en su buelo una media caña de la misma fabrica para adorno.

9. ${ }^{a}$ Que contra los Tirantes del Cuerpo de Yglesia se ha de hacer un Cielo raso con listones de tablas de ripia, clavados â tres dedos de clavo de uno â otro, y se han de tejer con tomizas, dejando jaarrado todo el Cielo raso con yeso negro, y en los rincones de las dos linias del Cuerpo de Iglesia contra los Tirantes se hara un Esquilfe encamonado, alistonado y tejido con tomizas en la misma forma, que el Cielo raso, y â de tener tres pies de buelo, y assi este, como el Cielo raso han de quedar blanqueados; y las nuevas paredes que se han de ejecutar jarradas, y blanqueadas por la parte interior, y bien palmeados los cajones de tierra, por la parte exterior.

$10{ }^{a}$ Que han de ser de quenta de la persona que se encargue de esta obra â toda costa, el poner de su quenta todos los materiales, que se necessiten hasta su perfecta conclusion; el hacer la demolicion de las armaduras, y paredes antiguas, que quedan mencionadas, y los baciados de sus cimientos; y toda la madera, que se necessite para andamios (que esta si puede serbir) podra ser de la que salga de las armaduras biejas. Y en caso de que no sirva serà de su quenta el ponerla nueva; quedando â beneficio suyo una, û otra, despues de finalizada la obra. Y tambien ha de poner todas las herramientas, clavazon, maromas de esparto, y demas cosas que sean precissas.

$11 .^{a}$ Que la cantidad en que se ajustare la referida obra se le ha de satisfacer en tres plazos, el primero luego, que se empiece, ô antes, para prevenir materiales, el segundo en estando rematadas las paredes del Cuerpo de Yglesia; y el tercero en estando finalizada la obra, y reconocida por persona inteligente, para su cumplimiento; dando la fianza que se tenga por mas proporcionada.

Madrid, y Octubre siete de mil setecientos, quarenta, y nuebe $=$ Medrano=.

A finales de ese mismo mes, el 31 de octubre de 1749, el escribano de la gobernación del Real Sitio, Alfonso Carralón, hizo llegar al gobernador de Aranjuez, el teniente coronel Baltasar José de Prado, las diligencias practicadas a favor de Florencio Rodríguez del Castillo, maestro alarife de la villa de Ocaña. Este se haría cargo de una obra ajustada en la cantidad de 16.712 reales, acatando las once condiciones de Juan Ruiz de Medrano y especificándose que "con la mejora de que las tapias proyectadas de tierra, las havia de hazer de mamposteria». La cantidad se libraría "sobre el caudal destinado para los texados del Palacio de Aranjuez", en pleno proceso de reconstrucción tras el incendio de $1748^{19}$.

19. Tovar Martín, Virginia. "El incendio del palacio de Aranjuez en el siglo XVIII". Anales de Historia del Arte, 1996, 6, pp. 47-65. 


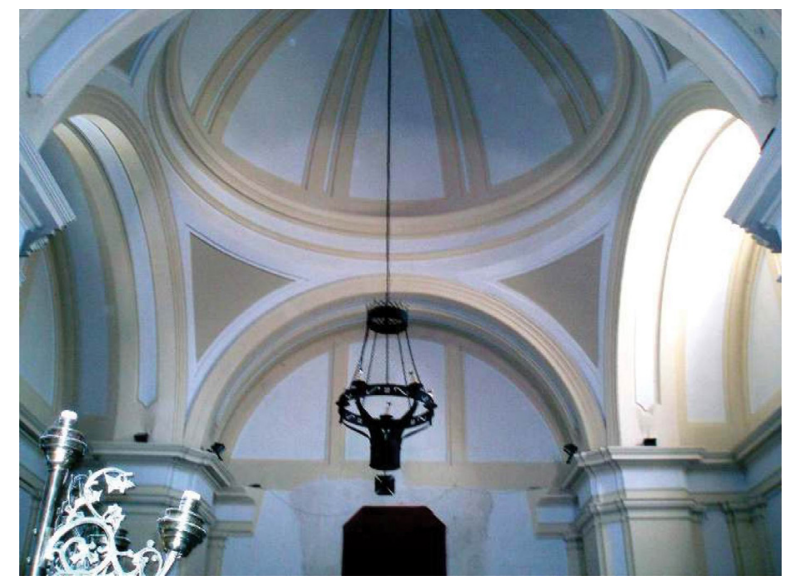

Interior del transepto de la iglesia, con la media naranja y las pechinas (estructuras desaparecidas en la actualidad).

Cuando todo parecía a punto para iniciar los trabajos, según recogen tanto el expediente del AGP como Juan Antonio Álvarez de Quindós, «el Cura, Alcalde, rexidor y el Procurador de la Villa de Ontigola» acudieron nuevamente al monarca, expresando:

[...] que haciendose dhos reparos en las mismas lineas que tenia la Igl.a no les aprovechava, por su estrechez y cortedad, y ser grande la necesidad que tenian de otra de maior extension, por haverse aumentado el num. ${ }^{\circ}$ de vezinos [...]

y por practicarse en Ontígola los enterramientos de la villa y los de Aranjuez. Por ese motivo, solicitaban que:

[...] pudiera la Villa hazer otra nueva en el atrio de la Vieja con el aumento de seis pies de ancho, y quinze o mas por largo, siendo a sus expensas de los vezinos el exceso del maior costo que tuviese sobre la cantidad en que estava hecho el remate de los reparos de la antigua.

La nueva petición fue cursada el 14 de diciembre de 1749, indicándose que era preciso dar orden al maestro mayor para que previera las modificaciones necesarias en planta y alzado, así como en materiales. A los requerimientos anteriores se añadieron nuevas condiciones. En primer lugar, todo el importe de la obra, tanto el caudal del rey como los fondos de la villa, había de depositarse en un arca con tres llaves en la Casa de Oficios de Aranjuez. En segundo lugar, la obra asumiría las reglamentaciones establecidas para las tareas realizadas en el Real Sitio y su «jefe privativo» sería el gobernador de Aranjuez. Otro de los requisitos fue que los vecinos habían de obligarse, "no solo en comun, sino en particular", a sufragar su parte de la construcción. 
El consistorio de Ontígola se reunió el 24 de diciembre de 1749 para debatir estos puntos y los aprobó, si bien puntualizaba que «la villa no tenia fondos existentes que entrar en la Arca de tres llaves, como se prevenia en la primera condicion». Para abaratar los trabajos, los ontigoleños se comprometieron:

[...] a concurrir a tan piadosa obra, unos sacando y produciendo Piedra, Pedernal, otros Piedra, Yeso, y conducir con sus Carruajes la madera, texa y otros materiales que el Maestro tenia que llevar de fuera, y los que no tenian carruaje estavan prontos a hacer ôrnos de Yeso, y sacar Piedra Yesso, arena \&.

Se especificaba que los vecinos podrían trabajar en el templo durante los días de fiesta, "sin que en los de trabajo, se les estorvase el ganar para comer".

Conformes los vecinos con las condiciones del maestro Florencio Rodríguez del Castillo para la ampliación de la iglesia y autorizadas las obras por el gobernador de Aranjuez, el camino parecía despejado el 16 de enero de 1750 para que todo comenzase. Manuel Pérez, vecino de la villa, sería el fiador de los trabajos, que se estimaba que superasen en 9.000 reales los 16.712 aportados por la Corona.

Sin embargo, una nueva dilación impidió comenzar. El 29 de enero de 1750, el arquitecto Juan Ruiz de Medrano puso dos reparos a las nuevas trazas de la iglesia que consideramos fundamentales para la elaboración de esta investigación y para comprender en nuestros días la morfología del edificio:

1. ${ }^{\circ}$ Que haviendose de demoler enteram.te toda la fabrica de la Igl.a antigua, quedava la nueva sin torre, ni sacristia, como se reconocia, por no estar demonstradas en la Planta letra: .Y. de la nueva Iglesia, yq para suplir la falta de dha Sacristia, se elegia en la pared de la nueva Iglesia la Puerta letra .N. para pasar al Presviterio de la Iglesia antigua, el qual parecia que aprovechandose de el, sin demoler las paredes de su testero, y costados, havia de servir de Sacristia, como se demostrava en las linias de puntos. Y tambien parecia que para suplir la falta de torre se elegia en la pared de la nueva Iglesia, la Puerta letra .M. para entrar y suvir a la torre, cuia fabrica parecia que tambien havia de quedar existente, y que haviendo de quedar usuales el Presviterio de la Iglesia antigua para sacristia de la Iglesia nueva, y tambien la torre de la Vieja para servirse de ella, havia que añadir mas obras de las que referia Florencio Rodriguez, asi para formar la sacristia en la Iglesia Vieja, dandola comunicazn a la nueva, como para servirse de la torre antigua, y que por esto era consiguientte que algun dia se pidiese mas cantidad que la considerada en el ajuste, por razon de mejoras. Y que si se demuelen las dos paredes laterales que forman el Cuerpo de la Iglesia antigua, quedara entre la torre, y sacristia toda la area que comprehenden para que sirvan de atrio, o, Plazuela, no dejando de causar vastante deformidad la separación de la torre y sacristia, en caso de q sean ciertas estas conjeturas.

2. ${ }^{\circ}$ Que en las condiciones que estendio dho Medrano para ejecutar los reparos de la Iglesia antigua, teniendo esta diez y ocho pies de hueco, se proponia que los tirantes havian de ser viguetas de 22 pies de largo, y que teniendo la nueva Iglesia que se intenta ejecutar 24 pies de hueco, no podian alcanzar las viguetas de 22 pies de largo propuestas, y que era preciso que las tirantes sean sexmas de buena ley, buen cuerpo y de 27 , u, 28 pies de largo para que alcanzen y engatillen las paredes 
y carreras, sobre que han de sentar, previniendose que aunque se aumenta el ancho de la Iglesia, siempre sirven para las armaduras, los pares de madera de ancho que expresan las condiciones de Medrano, por razon de que aunque alcanzavan por ellos madera de a diez, por ser febles, se consideraron de a ocho, y son los mismos que se deveran poner, que era lo que devia hazer presente segun su inteligencia.

El Archivo General de Palacio no conserva, desgraciadamente, las trazas levantadas por Florencio Rodríguez del Castillo, aunque estas pueden ser interpretadas a raíz de las condiciones impuestas por Juan Ruiz de Medrano, junto con la preservación de la torre y el aprovechamiento del presbiterio de la iglesia anterior.

Parece que los cambios asustaron al fiador y que Miguel Pérez protestó ante el arquitecto interventor por un desembolso económico mayor que los 9.000 reales previstos, si bien Juan Ruiz de Medrano, en carta a Miguel Herrero de Ezpeleta del 14 de febrero de 1750, planteaba que:

[...] vengo en Conozim.to de que, para que la Yglesia que nuebamente se ha de fabricar, tenga Sachristia y torre, hàn de aprovecharse, los dos testeros de la Iglesia Vieja, y parte de una pared colateral.

Especificaba a continuación el desarrollo definitivo a través de unas líneas de puntos, con sus letras, sobre la planta.

Desconocemos la finalización exacta de las obras, así como los avatares de las mismas, aunque consta en una de las visitas eclesiásticas del arciprestazgo de Ocaña, conservada en el Archivo Histórico Diocesano de Toledo, que en el año 1759 no habían finalizado aún las tareas de embaldosamiento y era necesario emplomar las cubiertas ${ }^{20}$. Se planteaba, además, que había de finalizarse el espacio del templo para albergar la pila bautismal y dedicar otro para archivo parroquial. Nuevas visitas realizadas en años posteriores, durante la década de los setenta, son tan parcas en este tipo de detalles que cabría suponer que la iglesia se encontraba ya finalizada. En el interior del campanario se conserva una inscripción con la fecha de $1784^{21}$, aunque desconocemos si se corresponde con la finalización de las obras o se trata de una restauración inmediatamente posterior.

El nuevo templo apenas mereció una breve mención por parte de Fernando Jiménez de Gregorio en otra de sus investigaciones, el Diccionario de los pueblos de la provincia de Toledo hasta finalizar el siglo XVIII, en donde manifestó escuetamente que:

20. Archivo Histórico Diocesano de Toledo (AHDT), Visitas, Ocaña, C. ${ }^{a} 1$.

21. Briones Toribio, Luis Bernardo; Corroto Briceño, Jesús y Maquedano Carrasco, Bienvenido. Las líneas del patrimonio..., vol. II, p. 138. 
[...] su iglesia está dedicada a la Purísima Concepción, perteneciendo su curato a la Orden de Santiago. En ella estandarte sacramental de raso blanco, bordado con hilo de oro; de estilo imperio, de finales del XVIII ${ }^{22}$.

No consta la desaparición de esta pieza entre los ornamentos del templo que fueron robados en 1884 y 1907, episodios que fueron recogidos tanto por $\mathrm{La} G a$ ceta de Madrid como por los periódicos de la época. Apenas conservamos detalles sobre el patrimonio mueble del nuevo templo (previsiblemente, muy humilde) ni sobre sus imágenes, si bien en 1788 se veneraba en Ontígola al "santísimo Christo de la Cruz a cuestas, y por otro nombre de la Salud de las almas ${ }^{23}$. Su fiesta se celebraba los días 3 y 4 de mayo. La Biblioteca Nacional, por otra parte, conserva una convencional estampa de la Virgen del Rosario, patrona de la localidad, que sería realizada por José Bonifaz en 1813-1815²4.

A comienzos del siglo XIX, Juan Antonio Álvarez de Quindós especificaba que el encargado de atender espiritualmente a los ontigoleños era un teniente de cura que recibía al año la cantidad de 100 ducados, dotación a la que habría que añadir los derechos derivados del pie de altar, según especificaban las visitas consultadas. A pesar de la vieja disputa jurisdiccional sobre las competencias del curato de Ontígola en la que tuvo que terciar el propio Arzobispado, el párroco de la localidad residía ahora en Aranjuez y delegaba sus obligaciones en un asistente $^{25}$. La situación sería similar tras la guerra de la Independencia, pues, según Fernando Jiménez de Gregorio, «el párroco de Ontígola tiene como aneja la iglesia de Alpajés, reside en Aranjuez y pone un teniente de cura en aquel lugar» ${ }^{26}$.

Antes de finalizar este apartado añadiremos, por tratarse de un espacio muy próximo a la iglesia de Nuestra Señora de la Concepción, la breve alusión de Juan Antonio Álvarez de Quindós a «una casa grande en Hontígola con cubas y tinajas para cocer vino", propiedad de la antigua encomienda de Alpajés:

[...] que ha durado hasta el año de 1782, que se demolió por no repararla, dando S.M. el terreno à la villa para ensanche de la plaza, y lo restante despojos por derribos à Lucas Gonzalo de las Casas, Escribano de su Ayuntamiento, que ha hecho otra en el propio sitio para su habitacion $[\ldots]^{27}$.

22. Jiménez de Gregorio, Fernando. Diccionario de los pueblos de la provincia de Toledo hasta finalizar el siglo XVIII. Toledo: Editorial Católica Toledana, vol. II, pp. 151-153.

23. Diario de Madrid, 29 de abril de 1788, p. 4.

24. José Bonifaz, VR, de la Milagrosísima Imagen de NS del Rosario que se venera en la Iglesia Parroquial de la Villa de Ontígola... Toledo (lámina), 1813-1815, Biblioteca Nacional, inv. 51733.

25. A comienzos de 1804, cuando había quedado vacante la plaza de capellán y se requería que los sacerdotes aspirantes fuesen necesariamente confesores, era su sueldo de 6 reales diarios. Diario de Madrid, 18 de febrero de 1804, p. 3.

26. JimÉNEZ DE GREGORIO, Fernando. La comarca..., p. 56.

27. Álvarez de Quindós, Juan Antonio. Descripción histórica..., p. 91. 
Dicho ayuntamiento fue descrito, cumpliendo los usos habituales de las casas consistoriales a finales del siglo XVIII, por Fernando Jiménez de Gregorio: «Una casa con Sala Consistorial, cárcel, pósito, con una habitación en donde vive el tendero, que renta 110 rls. de beneficiom ${ }^{28}$.

\section{EVOLUCIÓN POSTERIOR}

Gracias a Fernando Jiménez de Gregorio es posible conocer algunos detalles sobre la evolución demográfica y social de Ontígola durante los siglos XIX y $\mathrm{XX}$, aunque sin demasiada información sobre la iglesia. Nada de interés aparece sobre ella en la documentación del Archivo Histórico Diocesano relacionada con el arciprestazgo de Ocaña, ni entre los protocolos notariales conservados en el Archivo Histórico Provincial ${ }^{29}$. La población del municipio no había crecido significativamente tras la guerra de la Independencia. En 1825 vivían en Ontígola 430 personas, más los 45 habitantes de Oreja. La cifra disminuyó considerablemente en 1843, repuntando a partir de entonces. Ontígola pasaría a depender de Ocaña tras la nueva división provincial de 1833 y la creación de los partidos judiciales un año más tarde. El presupuesto municipal en 1847 era de 16.321 reales, cantidades equiparables a las de Noblejas y Villatobas, y muy por encima de los fondos anuales de Cabezamesada (3.000) y Ciruelos (7.000).

El chapitel de la torre de la iglesia -según Briones, Corroto y Maquedanoestaba en mal estado en 1850, amenazando la casa contigua a la iglesia. Eran necesarios 2.388 reales para la reparación de su fábrica y para adecuar la escuela municipal, suma que se proponía obtener de la venta de la leña del soto de Oreja. Finalmente, Joaquín García de Mora se hizo cargo de los trabajos por 1.980 reales. Nueve años después, la reina Isabel II realizaba a la iglesia una donación de 17.700 reales, «los mismos á que ascendía el presupuesto que de orden de nuestra piadosa y liberal soberana había formado la municipalidad de Ontígola para remediar las necesidades de localidad y culto que esperimentaba aquella pobre

28. Jiménez de Gregorio, Fernando. Diccionario de los pueblos..., vol. II, p. 152. También poseemos algunos detalles sobre la escuela del municipio, que regía un maestro de primeras letras. En el siglo XVIII percibía 1.200 reales anuales, suma que a comienzos del siglo XIX ascendía a 200 ducados anuales, más "casa en que vivir" y un sobresueldo que pagaban «los niños de leer que no sean pobres" de un real al mes, "y los de escribir y contar dos», aparte de un cuarto de real cada sábado (Diario de Madrid, sábado 18 de febrero de 1804, p. 195). Según Briones, Corroto y Maquedano, hasta más adelante no se construiría un edificio de fábrica, el cual estaba ya necesitado de reparación en 1850. Gabriel Flores de Ocaña realizaría diversas reparaciones en él un año después, aunque el hecho de ser insuficiente su capacidad para el número de niñas y no poseer habitación para la maestra hizo proponer una ampliación de las escuelas a un solar contiguo, hecho que según parece no se produjo.

29. Archivo Histórico Provincial de Toledo (AHPT), Protocolos, Ontígola, escribanos Félix Romero Gomara y Bonifacio González de las Casas (1824-1863). 
parroquia ${ }^{30}$. Es probable que esta suma fuese destinada a las nuevas obras de reparación emprendidas en 1865, "posiblemente en las cubiertas»"

El Instituto Geográfico Nacional conserva entre sus planos del municipio, realizados en 1880 por los topógrafos Estanislao Lacaci e Isidoro González, un buen levantamiento en planta del edificio, con una leyenda donde se detalla el uso de sus espacios (incluido un "Cuarto cuyas dimensiones no han podido medirse directamente por estar lleno de trastos», inmediato a la capilla del lado del Evangelio). La serie contiene también un completo plano del municipio y su cementerio, además de las representaciones en planta de la población de Oreja y de su pequeña iglesia, anteriormente mencionadas.

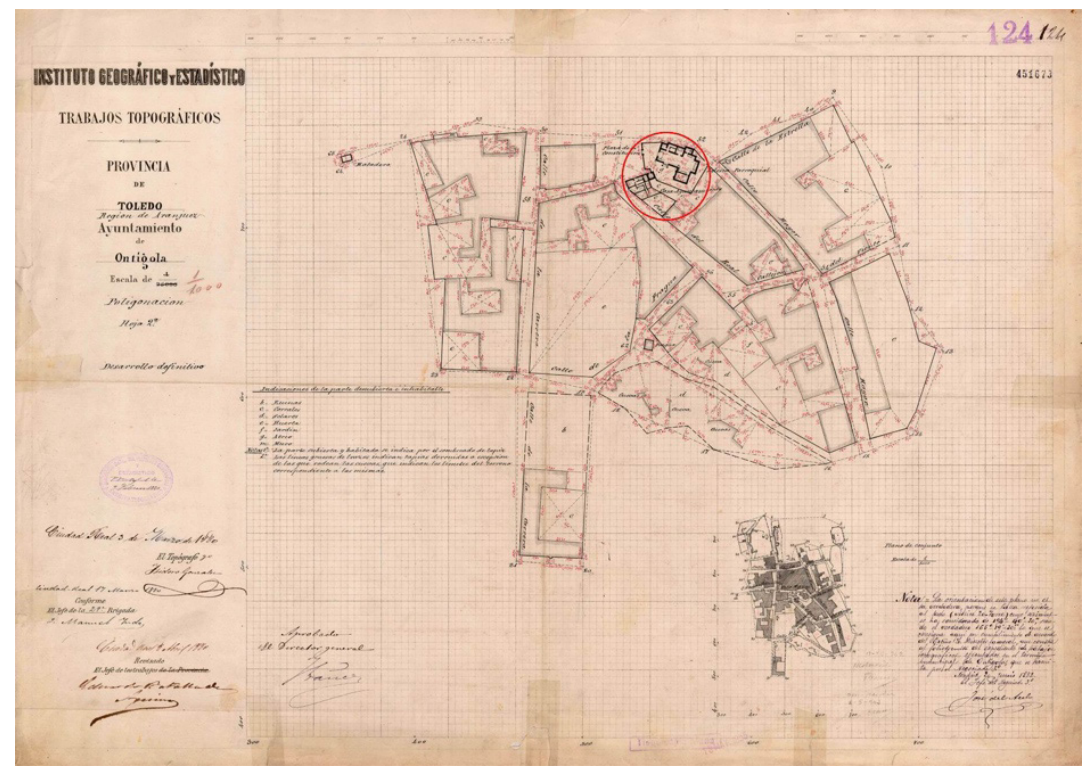

La iglesia y el ayuntamiento de Ontígola en una vista topográfica de 1880.

La noche del 30 de abril de 1884 se produjo el primero de los dos robos documentados en el templo. Las piezas sustraídas fueron:

Dos rosarios de cuentas negras, engarce y cruz de plata. Un cinturón de seda con botoncillos de plata. Una bandejita ochavada de metal dorado. Una cajita de plata de peso de tres onzas, conteniendo 20 Formas consagradas. Una crucecita con su

30. La Corona, 4 de agosto de 1859, p. 6.

31. Briones Toribio, Luis Bernardo; Corroto Briceño, Jesús y Maquedano Carrasco, Bienvenido. Las líneas del patrimonio..., vol. II, p. 138. 
Cristo de plata, la mitad superior de la cruz de metal blanco, que se hallaba en el altar mayor. Una cruz de metal blanco de una media vara de alta. Las Sacras del altar mayor con marco dorado. Un incensario de metal blanco con cadenas de plata.

\section{Además, fueron robados los siguientes textiles:}

El fleco de un paño de hombros y de una manga, que parecía de plata sobredorada, así como el de la misma clase que guarnecía el fleco del palio. Una túnica de terciopelo morado, con bordado de plata toda ella. Cinco albas, dos de ellas con encaje de tres cuartas de ancho. Dos sabanillas también con encaje. Una casulla morada con bordado de hilillo al parecer de oro. Y una sobrepelliz blanca ${ }^{32}$.

El 8 de julio de 1885, tras haber sufrido Ontígola las duras consecuencias de una epidemia de cólera, José M. Riuvadets publicó tres vistas de la población en La Ilustración Española y Americana ${ }^{33}$. En una de ellas puede apreciarse una panorámica general del municipio con la torre de la iglesia dominando el conjunto de edificios.

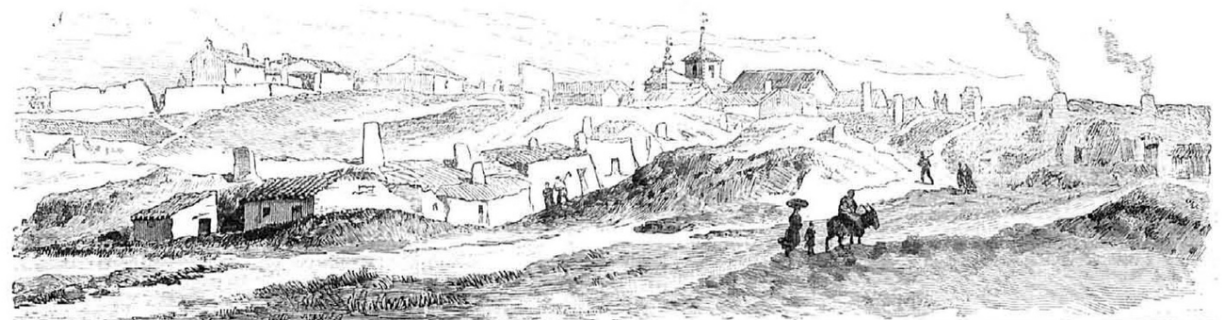

La iglesia de Ontígola en 1885, representada por José M. Riuvadets en La Ilustración Española y Americana.

32. Gaceta de Madrid, 13 de julio de 1884, p. 147. Antonio Campesino y Berrocal, juez de instrucción de Ocaña, dictaría el 5 de mayo orden de busca y captura contra "tres sujetos desconocidos" que la tarde del 29 de abril habían llegado a Ontígola, en tren, procedentes de Santa Cruz de la Zarza. «[...] fueron vistos en las afueras de la población por varios vecinos de la misma, sin que consten más señas que ser de una edad regular, sin barba, mal trajeados, vistiendo uno de ellos pantalón azul, otro pantalón de pana color café, y estos dos con mantas y gorras de las llamadas de piel de nutria, y el tercero con sombrero ancho y un capote de monte». El segundo robo del que tenemos noticia se produciría a comienzos de abril de 1907, cuando desapareció «una capa encarnada de coro; otra ídem blanca; otra ídem morada; dos paños de púlpito, morados; otro ídem de ídem, encarnado; un frontal blanco; una banda morada; otra ídem blanca; una casulla encarnada; un arete de viril, de plata sobredorada; un copón de metal blanco; una caja portaviáticos; una cortinilla del sagrario; un estandarte de seda bordada; un rosario de la Virgen, negro, y un dosel encarnado». Esta breve reseña, publicada en la prensa local de Toledo, finalizaba manifestando cómo «la Guardia Civil practica activas gestiones para capturar á los autores del robo» (El Castellano, 4 de abril de 1907). Casi treinta años más tarde, según testimonios orales, se produciría un nuevo expolio y destrucción de los ornamentos y enseres del edificio, incluidos el altar mayor y el órgano del coro. Tal vez en este contexto se produjera la restauración de la torre sugerida por una inscripción con la fecha de "1933", como plantearon Briones, Corroto y Maquedano.

33. La Ilustración Española y Americana, año XXIX, 25, 8 de julio de 1885. 
Su remate era un chapitel con aguja y veleta que el templo no conserva actualmente y que, sin embargo, se intuye en una antigua fotografía de la plaza de la Constitución a finales del siglo XIX, empleada hace algunos años para ilustrar un programa de fiestas ${ }^{34}$. En ella aparecía también el primitivo reloj municipal, instalado a mediados de la centuria junto con los de los municipios vecinos de Ocaña y Villatobas.

La iglesia parroquial de la Purísima Concepción no comenzó el nuevo milenio con buen pie. En el año 2004 fue cerrada al culto por amenaza de ruina. El retraso en la obtención de la correspondiente licencia de obras impidió iniciar una restauración que el Arzobispado de Toledo pretendía haber resuelto a finales de la década pasada. Desgraciadamente, el deterioro del templo obligó a demoler, con la autorización de la Junta de Comunidades de Castilla-La Mancha, la mitad correspondiente al lado de la Epístola, la torre y los pies. Desde finales de enero de 2020 se está restaurando.

\section{MORFOLOGÍA}

La iglesia de Nuestra Señora de la Concepción, como ya se ha recogido, es un pequeño templo barroco cuyo estado definitivo -parcialmente demolido en la actualidad, en espera de restauración- corresponde a la actuación de mediados del siglo XVIII, aunque reaprovechando estructuras anteriores, especialmente la cabecera y la torre. Posee planta de cruz latina de una sola nave, con transepto escasamente definido, una capilla en el lado del Evangelio, coro sobreelevado y torre a los pies, además de sacristía y dos estancias colaterales. La entrada principal, que previsiblemente se conservará, se encuentra situada a los pies del edificio, siguiendo el eje de la nave, aunque hasta hace escasos años existía también un acceso lateral a través de un pequeño pórtico, cubierto por un sencillo tejaroz.

El análisis de la planta permite apreciar una clara compartimentación espacial, característica de la arquitectura religiosa del siglo XVIII. Resultaba ambigua, sin embargo, la presencia de las dos estancias colaterales, espacios que parecían haber sido añadidos con posterioridad a la fábrica original y que consistían en un amplio salón rectangular situado a la derecha de la cabecera (hoy desaparecido) y el antiguo despacho parroquial, construido aprovechando el espacio resultante entre la torre de los pies del edificio y la pequeña capilla adosada a su flanco izquierdo. En ambos casos los materiales parecían ser de peor calidad-mampostería trabada con malos morteros-, con cubiertas de teja de un solo faldón. Por el contrario, un conjunto de sillares de ciertas dimensiones a la altura de la esquina exterior de la sacristía, escuadrados en el mismo material que los soportes del

34. LINDO MARTÍNEZ, José Luis. Grandes fiestas en honor a Nuestra Señora del Rosario (programa de fiestas). Ontígola, 2007. 
pórtico lateral, sugiere mayor solidez constructiva que el resto, al tiempo que mayor antigüedad. Se trataba de piezas labradas en la célebre "piedra almendrilla" -de «las canteras frente à Ontigola»- a la que aludieron tanto Juan Antonio Álvarez de Quindós como Pascual Madoz, quien recordaba que este material había sido empleado también en la construcción de la Casa de Oficios de Aranjuez ${ }^{35}$.

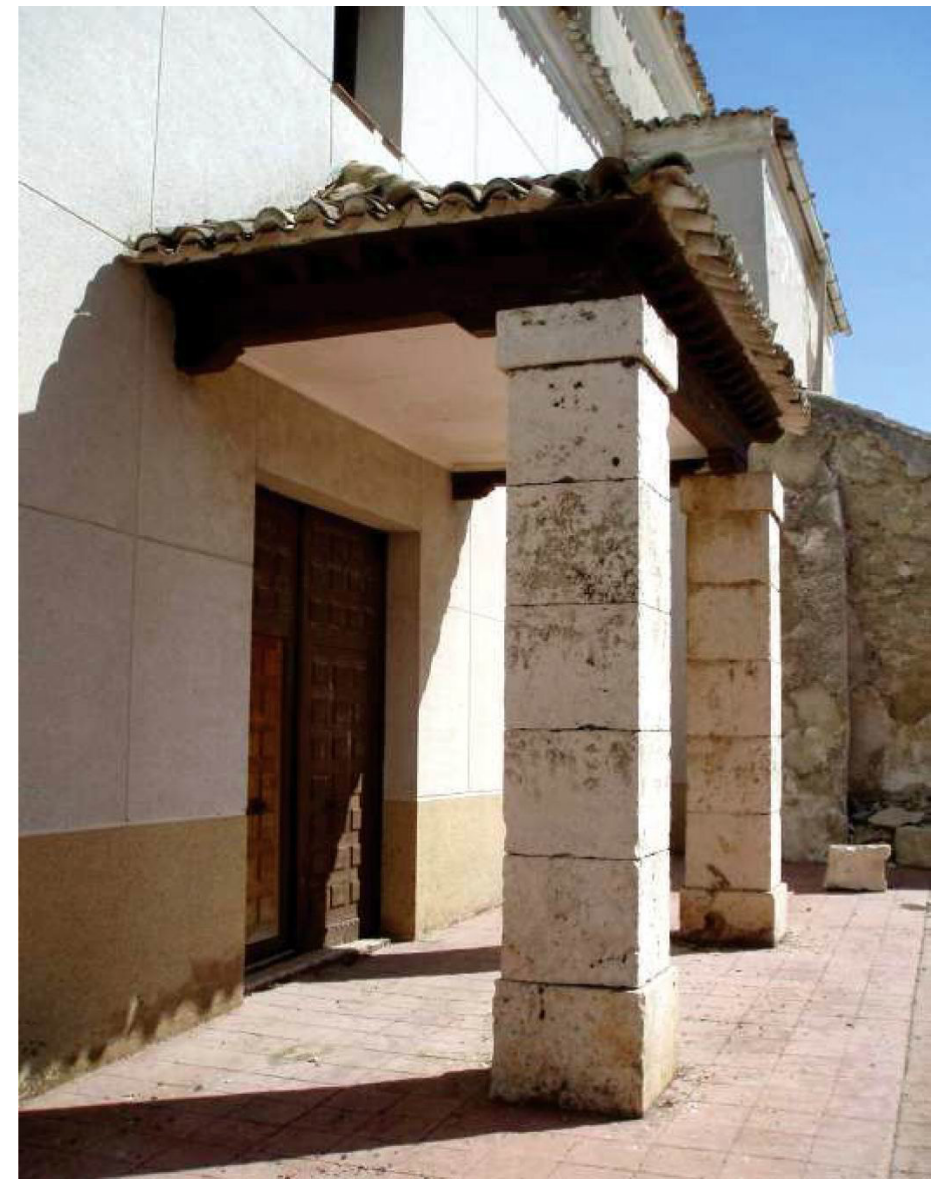

Pórtico lateral, sustentado por sendos soportes de "piedra almendrilla" procedente de las canteras locales y empleada en diversas obras del Real Sitio.

35. MAdoz, Pascual. Diccionario..., vol. II, p. 432. 
De la misma "almendrilla», compactación de rocas metamórficas a menudo empleadas en obras civiles durante la Edad Moderna en esta zona de España, eran también los dos soportes del pórtico lateral, de incierto futuro al haber sido demolida esta parte de la iglesia. Se trataba de sendas columnas de sección cuadrada formadas por cinco tambores, con sus correspondientes basas y capiteles, apenas esbozados, que parecían contemporáneas a la fábrica original del edificio y denotaban la influencia constructiva de las edificaciones del Real Sitio de Aranjuez, especialmente las arcadas de la Casa de Oficios, construidas en el siglo XVI. El tono de estos sillares era un melado muy similar a las piezas que componen la esquina de la sacristía. Dicho pórtico se encontraba cubierto por un tejaroz a tres aguas, con carreras y canecillos de madera sin gran interés.

La mayoría de las cubiertas del templo estaban compuestas por dobles faldones sustentados por parhileras de madera. La sencillez de las molduras exteriores no permite definir con exactitud qué zonas del edificio formaban parte de la construcción del siglo XVIII y cuáles fueron añadidas después, si bien hasta las recientes obras se conservaban los medios boceles y el listel del cuerpo que sobremontaba el crucero, con ladrillos aplantillados en el exterior del presbiterio y los brazos del transepto. La media naranja, hoy también desaparecida, estaba cubierta por un cuerpo encamonado que podía apreciarse a cuatro aguas desde el exterior. Obviamente, no se conserva vestigio alguno del estilizado chapitel que la iglesia aún conservaba en el siglo XIX.

El interior del templo constaba de una sola nave cubierta por una bóveda de cañón con cuatro tramos resueltos por dos fajones y sendos lunetos, bien definidos aunque insinuados con escaso resalte. La intersección entre la nave y el pequeño transepto era muy poco acusada. Tanto el testero del presbiterio como los dos brazos perpendiculares del crucero eran planos y no llegaban a formar capillas debido a su escasa profundidad. Estaban rematados por vanos termales, perforados en sus laterales. En el altar mayor, la sección central del vano termal era ciega y hasta hace poco estuvo ocupada por un lienzo de la Virgen que la parroquia conserva todavía, y que presumiblemente volverá a su lugar una vez finalizadas las actuales obras de restauración. El crucero estaba rematado por una media naranja sustentada por pechinas sobre machones decorados con pilastras de escaso resalte. El entablamento corrido de estas, parcialmente conservado, recorría el interior de la nave.

La capilla situada en el lado del Evangelio es un pequeño edículo de planta cuadrada cubierto por una media naranja similar a la del crucero, aunque más barroquizante. 


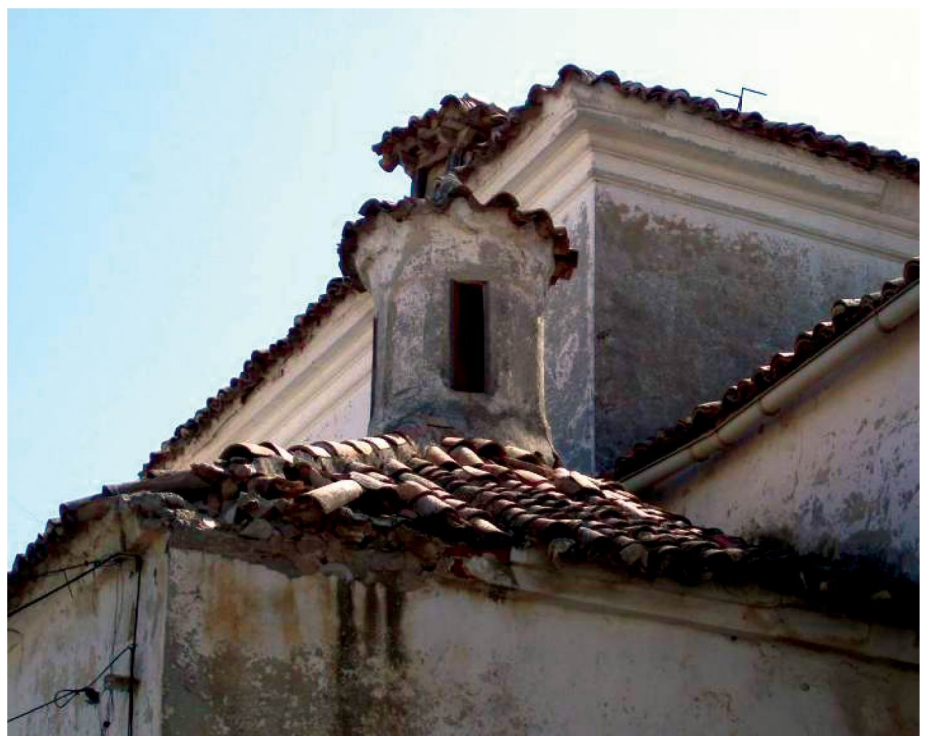

Estado de la cubierta de la capilla barroca de la zona del Evangelio, rematada por un pequeño linternín.

A la bicromía de sus enlucidos se suma el enmarque de las pechinas por medio de cordones y hojas de roble, así como el retablo que preside este espacio.

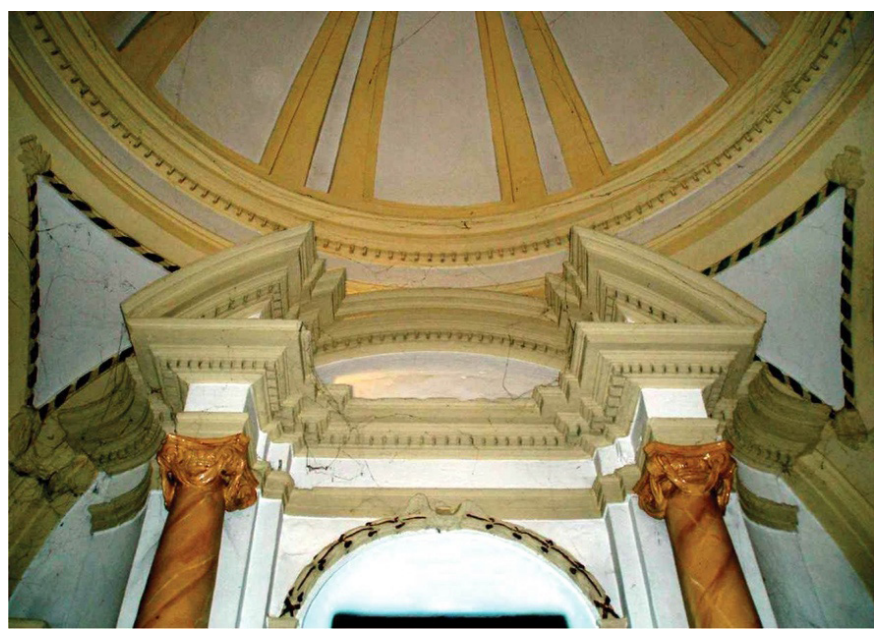

Interior de la capilla barroca, con el remate superior del retablo barroco-clasicista, rematado por un frontón curvo y partido. 
Desde el exterior, esta capilla puede apreciarse como una pequeña construcción situada junto a la sacristía y coronada por un linternín de obra con diseño de recercados verticales que alternan con estrechas y alargadas ventanillas. Preside este espacio un pequeño altar de factura clasicista, rematado en un frontón curvo partido sobre dos soportes de orden jónico. El diseño de esta estructura es similar a otros altares de estuco a imitación de jaspes realizados en la segunda mitad del siglo XVIII, tanto en el entorno cortesano de Aranjuez como en la sede arzobispal toledana, aunque su tosca factura, probablemente remozada con posterioridad, impide establecer conclusiones. No se han conservado otros elementos similares, a excepción de los altares-hornacina de dos columnas y coronamiento semicircular antes situados en la nave de la iglesia, a todas luces mucho más recientes. El altar mayor, en este último periodo del templo, no poseía retablo ni adorno alguno, a excepción de un vano termal bajo la bóveda de cañón en donde estaba el óleo de Nuestra Señora antes mencionado.

Del interior de la iglesia queda por explicar el pequeño aunque desahogado coro de los pies, que hoy se encuentra vacío, sin presencia de sillería ni tampoco órgano. Antes de las obras estaba comunicado con la nave del templo a través de un pequeño acceso que rompía, en forma de arco rebajado, la línea corrida del cornisamento interior del edificio.

La torre posee tres cuerpos en ascensión decreciente, el último de ellos campanario. Su factura resulta anterior al siglo XVIII. Del cuerpo campanario cabe destacar únicamente el diseño de sus cuatro ventanas de medio punto, ligeramente adelantadas -al igual que las pilastras esquineras de las líneas verticales de la estructura- y con claves y salmeres en resalte.

\section{FINAL INCIERTO}

En fechas muy recientes, el 25 de enero de 2020, el arzobispo Braulio Rodríguez (recién jubilado por edad y en calidad de administrador eclesiástico de la archidiócesis a la espera de su sucesor, Francisco Cerro) bendijo la primera piedra de su definitiva restauración ${ }^{36}$. Este proceso, con un presupuesto estimado de 1.800.000 euros y a partir del proyecto de José Luis Montero Escobar, arquitecto diocesano, estaba previsto que finalizase a mediados del año 2021. El estado de alarma provocado por la epidemia de COVID-19 y la paralización de las actividades no esenciales, sin embargo, mantiene abierto el futuro del monumento, un templo íntimamente ligado al Real Sitio de Aranjuez que sin duda habría merecido mejor suerte.

36. PACheCo, Juan F. «Don Braulio bendijo la primera piedra del nuevo templo parroquial de Ontígola", web del Arzobispado de Toledo (www.architoledo.org/noticias/don-braulio-bendijo-laprimera-piedra-del-nuevo-templo-parroquial-ontigola), consultada el 14/06/2020. 